\title{
BNC para formação docente: um avanço às políticas neoliberais de currículo
}

\author{
BNC for teacher education: an advance to \\ neoliberal curriculum policies
}

\section{BNC para la formación docente: un avance a las políticas curriculares neoliberales}

\author{
Manuella de Aragão Pires ${ }^{1}$ \\ Lívia de Rezende Cardoso ${ }^{1}$
}

DOI: http://dx.doi.org/10.20435/serie-estudos.v0i0.1463

\begin{abstract}
Resumo: Este artigo analisa os documentos que compõem o processo de construção da Resolução CNE/CP n. 2, de 20 de dezembro de 2019, perpassando desde a primeira proposta para Base Nacional Comum da Formação de Professores da Educação Básica até o parecer final do CNE e a resolução que define as Diretrizes Curriculares Nacionais para a Formação Inicial de Professores para a Educação Básica e institui a Base Nacional Comum para a Formação Inicial de Professores da Educação Básica (BNC-Formação). Argumentamos que tais documentos instituem uma racionalidade neoliberal para pensar, por meio da lógica das competências, um currículo que produz subjetividades docentes e discentes alinhadas às regras de mercado. Para tanto, discutimos a responsabilização docente como estratégia para justificar e instituir um currículo que diz salvar a educação brasileira de seus principais problemas. Mostramos velhas competências liberais na docência a serem retomadas destituindo conquistas educacionais. Evidenciamos o perfil prático, que desvaloriza as teorias, demandado aos docentes.
\end{abstract}

Palavras-chaves: currículo; formação docente; BNC.

Abstract: This article analyzes the documents composing the construction process of the Resolution CNE/CP (National Council for Education/Plenary Council) n. 2, December 20, 2019, going through the first proposal of the National Common Base of Basic Education Teacher Training, until the final CNE Opinion and the resolution that defines the National Curriculum Guidelines for the Initial Teacher Training for Basic Education (BNC-Formação). We argue that such documents establish a neoliberal rationality for thinking, through the logic of competences, a curriculum that produces subjectivities for teachers and students in line with market rules. To this end, we discuss teacher accountability as a strategy to justify and institute a curriculum that is said to save Brazilian education from its main problems. We show that old liberal skills in teaching are resumed, destroying educational achievements. We highlight the practical profile, which devalues theories, demanded of teachers.

1 Universidade Federal de Sergipe (UFS), São Cristóvão, Sergipe, Brasil. 
Keywords: curriculum; teacher education; BNC.

Resumen: Este artículo analiza los documentos que componen el proceso de construcción de la Resolución CNE/CP (Consejo Nacional de Educación/Consejo Pleno) n. 2, de 20 de diciembre de 2019, poniendo atención para el lugar que ocupa la diversidad en ella, pasando desde la primera propuesta de la Base Nacional Común de Formación Docente de la Educación Básica, hasta el dictamen final del CNE y la resolución que define las Directrices Curriculares Nacionales para la Formación Inicial Docente para la Educación Básica. Argumentamos que tales documentos instituyen una racionalidad neoliberal para pensar, a través de la lógica de las competencias, un currículo que produce subjetividades para docentes y estudiantes en línea con las reglas del mercado. Con este fin, discutimos la responsabilidad de los maestros como una estrategia para justificar e instituir un plan de estudios que dice salvar a la educación brasileña de sus principales problemas. Mostramos que las viejas habilidades liberales en la enseñanza se reanudan, destruyendo los logros educativos. Destacamos el perfil práctico, que devalúa las teorías, exigidas a los docentes.

Palabras clave: currículum; formación del profesorado; BNC.

\section{INTRODUÇÃO}

Este artigo analisa os documentos que compõem o processo de construção da Resolução CNE/CP n. 2, de 20 de dezembro de 2019, que define as Diretrizes Curriculares Nacionais para a Formação Inicial de Professores para a Educação Básica e institui a Base Nacional Comum para a Formação Inicial de Professores da Educação Básica (BNC-Formação). A análise transcorrerá desde a primeira proposta da Base Nacional Comum da Formação de Professores da Educação Básica (BRASIL, 2018), lançada em dezembro de 2018, no governo de Michel Temer, passando pela 3a versão do Parecer do CNE (BRASIL, 2019a), disponibilizada para consulta pública em 18 de setembro de 2019, no governo de Jair Messias Bolsonaro, até a versão final deste documento, que é o Parecer CNE/CP n. 22/2019 (BRASIL, 2019b), e a resolução CNE/CP n. 2, de 20 de dezembro de 2019 (BRASIL, 2019c), vinculada a ele.

A análise aqui proposta compreende currículo como aquilo que é historicamente construído por meio de disputas políticas e de diferentes projetos de educação e nação, de forma que a seleção e a organização dos conhecimentos tidos como importantes são realizadas com base em princípios e valores estabelecidos nas relações de saber-poder com o propósito de produzir subjetividades desejadas. Assim, consideramos que o currículo não está dado e não é constituído de forma ingênua e neutra, de maneira que "aquilo que está inscrito nele não é 
apenas informação - a organização do conhecimento corporifica formas particulares de agir, sentir, falar e 'ver' o mundo e o 'eu'” (POPKEWITZ, 1994, p. 172).

O currículo surgiu como uma invenção da sociedade ocidental, junto do projeto de escolarização, em um contexto histórico de transformações da modernidade, com a finalidade de regular e disciplinar o indivíduo conforme padrões de valores religiosos, morais e sociais esperados para o momento e, então, tornar possível um modelo de sociedade (POPKEWITZ, 1994). Nesse contexto, "domesticar, normalizar e fazer produtivos os sujeitos era mais rentável do que segregá-los ou eliminá-los" (VARELA, 1999, p. 81). Desse modo, não por meio de uma força repressora, mas de forma sutil, as instituições educativas, ou seja, o currículo, perante suas regras, hierarquizações e classificações, produzem socialmente indivíduos e saberes desejados.

Um modo de refletir acerca dos efeitos de poder sobre os corpos e sobre a vida na sociedade ocidental foi introduzido nas ciências humanas e sociais por meio dos estudos de Michael Foucault. Para além da compreensão do controle dos corpos e das instituições, sua análise foi ampliada em meados dos anos de 1975 para o domínio da vida e de sua gestão. Ligada à tecnologia disciplinar, surgiu a estratégia biopolítica de regulação da vida, tendo a educação e, portanto, o currículo como tecnologia de governamento (RESENDE, 2018). Assim, um modo de construir currículo é "usado para produzir sujeitos que empresariam as suas vidas" (CARDOSO, 2018, p. 952).

Nesse sentido, Foucault (2008) toma o liberalismo, analisando-o não simplesmente por uma perspectiva econômica, mas a partir da ideia de racionalidade governamental. Ele mostra como o funcionamento do liberalismo se opôs à razão de Estado, instituindo-se como prática política que limitava a ação do Estado e como um gerenciador das liberdades. O neoliberalismo, por sua vez, atualiza tais noções e intensifica as relações de governo de si e dos outros por meio da noção de concorrência, "um jogo formal das desigualdades" (p. 163) e de "sociedade empresarial" (p. 333). O neoliberalismo é compreendido por Foucault como uma racionalidade, "uma maneira de ser e de pensar" (p. 301).

É a partir dessa ampliação da análise foucaultiana para a governamentalidade que compreenderemos as nuances da engrenagem das políticas de reformas curriculares neoliberais brasileiras na contemporaneidade, das quais os documentos aqui analisados fazem parte. Para Haroldo de Rezende, o Estado Neoliberal é 
[...] gerido pela invenção de crises que funcionam como tecnologias de governo que conduzem o modo de agir dos indivíduos e encontram na educação, entendida em variados aspectos e diferentes abrangências, um poderoso instrumento biopolítico de governamento que faz com que termos como reforma, ajuste, competitividade, empreendedorismo, desregulamentação, mercado, consumidor, terceirização e empresa, por exemplo, ressoem como únicos sentidos possíveis. (RESENDE, 2018, p. 12).

Sendo assim, tais racionalidades políticas, que são "estilos de pensamento, modos de tornar a realidade pensável de tal maneira que resulte maleável ao cálculo e à programação" (MILLER; ROSE, 2012, p. 27), específicas do neoliberalismo, modelam condutas de indivíduos e de grupos por meio de tecnologias de governo, sendo o campo educacional um locus privilegiado. Dentro dessa égide neoliberal, existem duas dimensões: o governo do outro e o governo de si. Este último é o que torna possíveis as resistências, já que, apesar do efeito das relações de poder, o indivíduo também age sobre si mesmo, podendo subverter (GALLO, 2018).

As bases e diretrizes nacionais de currículos produzidas configuram-se como uma política de governo dos outros e governo de si. E, para entendermos seus raciocínios e sujeitos desejados, é preciso entender sobre as condições que fizeram emergir os currículos sobre os quais refletiremos.

Desde o golpe de Estado em 2016, no Brasil, que culminou no impeachment da então presidente Dilma Rousseff, partidos políticos que apoiaram o golpe passaram a ter grande participação no governo de Michel Temer. Como exemplo, o Partido da Social Democracia Brasileira (PSDB), que nesse período ocupou cargos importantes no MEC, retomando fortemente projetos educacionais da época do governo Fernando Henrique Cardoso, a exemplo da reforma nas políticas educacionais de currículo ancorada na perspectiva das competências e habilidades que, em 2002, alicerçaram as primeiras Diretrizes Curriculares Nacionais para a Formação de Professores da Educação Básica, em nível superior, curso de licenciatura de graduação, conforme a Resolução CNE/CP n. 1, de 18 de Fevereiro de 2002. Após décadas de estudos e debates críticos dos pesquisadores em educação contrários à concepção dessa resolução, treze anos depois ela é revogada pela Resolução n. 2, de 1o de julho de 2015.

Segundo a Associação Nacional de Pós-Graduação e Pesquisa em Educação, foi também após o golpe de 2016 que a forma de conduzir os debates para a construção de Políticas Públicas para Formação de Professores por parte do 
MEC passou a caracterizar-se por uma pressa nas decisões, falta de definição de critérios e utilização de uma metodologia em que "os debates são minimizados, as participações da comunidade acadêmica reduzidas e o compromisso com a democracia e com o público na educação pública se esvai " (ANPEd, 2018, p. 9).

Foi assim que, em dezembro de 2018, o MEC lançou a Proposta de BNC para a Formação de Professores da Educação Básica e, em 8 de abril de 2019, o CNE convocou uma Comissão Bicameral, composta por 10 membros, para conduzir reuniões e debates com agentes da Educação brasileira, com o objetivo de revisar e atualizar a Resolução CNE/CP n. 02/2015 (BRASIL, 2015), bem como instituir a BNC de Formação Docente, sob a justificativa da necessidade de atendimento à legislação educacional, às novas demandas contemporâneas e às novas proposições da BNCC (BRASIL, 2017). Destaca-se que quase 100\% dos membros dessa comissão bicameral têm vínculo com a esfera privada de educação e setores e movimentos empresariais, como o Todos pela Educação e Todos pela Base, tendo apenas dois integrantes vinculados à rede pública de ensino. Entre as instituições, estão as de Ensino Superior privado, empresas educacionais de capital aberto, o Sistema S, organizações do mercado de material didático e tecnologias, e, além dessas, há também ligação de tais membros com organizações multilaterais, como a OCDE e a Unesco (TITTON; EVANGELISTA; FIERA, 2019).

É assim que as políticas curriculares educacionais brasileiras seguem o que estabelecem os países desenvolvidos, num discurso que forma os objetos de que fala e enuncia que, para entrarmos no processo de globalização com equidade em relação aos outros países e deixarmos a condição de subdesenvolvimento, é preciso que o nosso sistema educacional supere sua defasagem.

Dessa forma é que, após debates aligeirados acerca da primeira proposta ${ }^{2}$ da BNC-Formação, apenas a 3a versão do parecer foi publicizada em setembro de 2019 para consulta pública, a ser encerrada em 23 de outubro, culminando em dezembro de 2019 na homologação do parecer final e na resolução da BNCFormação, revogando a DCN 02/2015.

2 Os termos "proposta", "proposta inicial" e "proposta da BNC" se referem ao documento (BRASIL,2018); Os termos " 3 a versão" e " 3 a versão do parecer" se referem ao documento (BRASIL, 2019a); Os termos "versão homologada do parecer" e "parecer homologado" se referem ao documento (BRASIL, 2019b); e os termos "resolução homologada", "resolução" e "resolução da BNC" se referem ao documento (BRASIL, 2019c). 
Nesse cenário, argumentamos que as diretrizes curriculares nacionais para a formação inicial docente da educação básica operam uma racionalidade neoliberal para pensar, por meio da lógica das competências, um currículo que produz subjetividades docentes e discentes alinhadas às regras de mercado. Para desenvolver tal argumentação, dividimos o artigo em mais quatro seções. A seguir, discutimos a responsabilização docente como estratégia para justificar e instituir um currículo que diz salvar a educação brasileira de seus principais problemas. Depois, mostramos, a partir dos documentos, velhas competências liberais na docência a serem retomadas, destituindo algumas conquistas educacionais. Como consequência, evidenciamos em seguida o perfil prático demandado aos docentes. Por fim, construímos algumas considerações finais a partir das análises aqui empreendidas.

\section{RACIONALIDADE NEOLIBERAL DE RESPONSABILIZAÇÃO}

A necessidade de tal BNC foi justificada no 10 capítulo de tal proposta pelo que esta chamou de "evidências" surgidas a partir dos resultados de pesquisas e estudos nacionais que apontaram o mau desempenho dos alunos brasileiros no Ensino Fundamental e no Ensino Médio em avaliações, bem como "evidências" surgidas por meio de pesquisas internacionais realizadas por instituições como a Organização para a Cooperação e Desenvolvimento Econômico (OCDE) e a empresa de consultoria empresarial americana McKinsey \& Company, as quais consentem na ideia de que "a qualidade dos professores é a alavanca mais importante para melhorar os resultados dos alunos" (BRASIL, 2018, p. 6). Ou seja, as pesquisas postulam que os professores constituiriam um dos fatores de maior impacto no problema da aprendizagem.

O discurso de responsabilização docente quanto ao melhor desempenho dos alunos é presente em todo este documento e frequente na política educacional brasileira há décadas, configurando-se como uma tecnologia de governo neoliberal. Percebe-se que, a partir do argumento fundamentado em estudos e pesquisas internacionais, intenta-se dar legitimidade ao discurso, de forma que essa verdade é produzida e repetida para justificar a necessidade de reformas no currículo de formação. Esses estudos de especialistas atuam "tanto para construir os problemas sociais para os quais a ação governamental é dirigida quanto para ativamente regular, controlar, coordenar os alvos ali estabelecidos" (ROSE, 
1998, p. 38), que, nesse caso, são os sujeitos docentes. Isso faz mobilizar o desejo desses em se envolverem e acatarem o discurso, pois "é através da ativação de ideias, esperanças e temores das pessoas que as suas condutas são reguladas" (BAMPI, 2000, p. 15).

A instituição de avaliações e metas para a qual se deve voltar a atividade pedagógica do docente numa concepção de que educação de qualidade é a que corresponde com êxito às padronizadas avaliações instituídas, as quais são elaboradas em parceria com organizações internacionais baseadas em comparações com sistemas educacionais de países desenvolvidos, é também um discurso de responsabilização do docente que funciona como tecnologia do eu. O teor salvacionista, de que basta o estabelecimento dessa BNC na forma como está posta, para que os problemas da educação brasileira sejam resolvidos, pretende formar uma subjetividade autorresponsável e seduzir o sujeito docente para a conformidade com a proposta. Isso está explícito também na contextualização dos pareceres em que se discorre sobre os desafios que o país enfrenta na carreira do magistério, como a escassez de licenciandos pelo desprestígio da profissão, estruturas curriculares de formação fragmentadas com formação abreviada e mostrando a evolução dos indicadores dos sistemas educacionais de dez países por meio de suas diretrizes curriculares.

Por meio do currículo de formação, quer-se governar as práticas dos professores, determinando conteúdos e regras para atuação deles, sob o olhar e a exigência das políticas internacionais, para produzir determinados tipos de subjetividades docentes que sejam úteis para a manutenção da lógica desse projeto de educação. Com isso, tais docentes poderiam mais facilmente aderir em sua prática profissional à formação de recursos humanos em detrimento da formação de sujeitos. Uma lógica neoliberal que coloca o problema da sociedade na melhoria do "capital humano" (FOUCAULT, 2008, p. 314).

A educação está, pois, submetida à economização imposta pela contemporaneidade, e as políticas públicas estão invadidas pelos jogos e interesses do mercado que as define (VEIGA-NETO, 2018). O discurso neoliberal produz verdades sobre a formação docente e reitera que essa deve estar direcionada a atender às "demandas contemporâneas". Porém, apesar de em seus enunciados denunciar o desprestígio da profissão docente, desconsidera problemas socioeconômicos que interferem na educação, como a falta de estrutura para práticas pedagógicas, 
precarização do trabalho do professor e realidade social dos alunos, desvalorizando saberes locais, naturalizando as desigualdades e reforçando a exclusão.

A proposta da BNC pretendia redefinir ainda a formação continuada do professor, na qual esse, ao longo da carreira, deveria desenvolver habilidades e competências a serem comprovadas mediante empenho ou titulação, passando por quatro níveis de proficiência: o Inicial (nível do docente novato que ingressou mediante desempenho no Enade, prova nacional, concurso local ou outra forma de avaliação); o Probatório (para o ingressado que deverá apresentar novas competências e habilidades); o Altamente Eficiente (o docente que estará na carreira mais avançada); e, por último, o Líder (o docente que estará no nível mais alto da carreira e tem responsabilidades e compromissos mais amplos). As ações de formação continuada poderiam ser realizadas por meio da escola, das redes estaduais ou municipais, ou por ações externas, como cursos de pós-graduação, congressos etc.

Percebe-se aí a racionalidade de responsabilização do docente pelo seu desempenho, pela sua autoformação, pela busca constante de conhecimento, bem como a intenção de controlar, por meio das competências exigidas e por meio de avaliação, não apenas o percurso curricular de formação docente como também sua carreira no magistério, desde seu ingresso à permanência. Além disso, os termos Eficiente e Líder, utilizados para designar os níveis de proficiência na proposta, demonstram as bases sobre as quais o documento foi construído, termos que nos remetem ao campo empresarial e à lógica de mercado. Consta na proposta:

Da mesma forma que a formação, a carreira do professor se articula à Base Nacional de Formação. [...] As competências auxiliam na construção de uma trajetória profissional que envolve aspectos relativos ao desenvolvimento e à avaliação de desempenho, fundamentais para a qualidade do trabalho docente. (BRASIL, 2018, p. 40).

O docente novato, ao ingressar na escola, passaria pelo estágio probatório, com acompanhamento do mentor (professor experiente da escola) que o auxiliaria em suas atividades. Para passar do estágio probatório, ele deveria desenvolver competências previstas na matriz da BNC, apresentar um portfólio, ser avaliado pelo mentor e, por fim, pela equipe gestora da escola. Esse discurso de progressão por competências constitui a racionalidade neoliberal, quer governar o sujeito 
docente conforme as exigências do mercado, ao mesmo tempo que estimula a competição e desarticulação do professor. Na terceira versão do parecer da BNC, na versão homologada e na resolução a ele vinculada, foi excluída a menção à formação continuada e ao plano de carreira docente, que ficará a cargo de outra normativa a ser aprovada posteriormente pelo MEC.

A proposta traz ainda um conjunto de competências alicerçadas na BNCC e que devem ser alcançadas pelo docente em formação. A Matriz de Competências, como é chamado, constitui-se de dez competências gerais e 12 competências profissionais, que juntas reúnem 53 competências específicas distribuídas em três dimensões: dimensão do conhecimento profissional, que diz respeito a ter domínio do conteúdo, bem como saber ensinar; dimensão da prática profissional, cujo docente deve saber planejar ações que resultem em aprendizagem efetiva; e, por último, a dimensão do engajamento profissional, na qual o professor deve se comprometer com seu desenvolvimento profissional e com a aprendizagem do aluno, engajando-se com as famílias, colegas de escola e comunidade. A autorresponsabilização docente, mais uma vez, aparece em destaque no documento, compondo aqui uma das três dimensões centrais de sua prática, o "engajamento profissional".

\section{VELHAS COMPETÊNCIAS PARA A NOVA DOCÊNCIA}

A terceira versão do parecer e sua versão homologada trazem em geral o mesmo bojo da proposta inicial com relação à estrutura curricular, diferenciando-se desta última por apresentar um detalhamento da distribuição da carga horária dos cursos, nas etapas de formação, bem como conteúdos, competências e habilidades de cada etapa. Que são:

Grupo I: 800 (oitocentas) horas para a base comum que compreende os conhecimentos científicos, educacionais e pedagógicos e fundamentam a educação e suas articulações com os sistemas, escolas e práticas educacionais. Grupo II: 1.600 (mil e seiscentas) horas para a aprendizagem dos conteúdos específicos das áreas, componentes, unidades temáticas e objetos de conhecimento da BNCC e para o domínio pedagógico desses conteúdos. Grupo III: 800 (oitocentas) horas para a prática pedagógica com a seguinte distribuição: 400 (quatrocentas) horas de estágio e 400 (quatrocentas) horas para os componentes curriculares dos Grupos I e II, das quais:- 400 (quatrocentas) horas de estágio supervisionado, em situação real de trabalho em 
escola, segundo o Projeto Pedagógico do Curso (PPC) da instituição formadora;- 400 (quatrocentas) horas de práticas nos componentes curriculares dos Grupos I e II, distribuídas ao longo do curso, desde o seu início, segundo o PPC da instituição formadora. (BRASIL, 2019b, p. 23).

As aptidões da BNCC se constituem em tópicos, de forma a atingir mais de $50 \%$ da carga horária dos cursos de licenciatura, e são descritas nos pareceres e na resolução, estando vinculadas à necessidade de que os professores adquiram competências profissionais ligadas a elas em um "aprendizado permanente" diante da complexidade da contemporaneidade, de maneira que aos estudantes da Educação Básica sejam garantidas as "aprendizagens essenciais" previstas nesse novo currículo comum nacional (BRASIL, 2019b). Destaca-se que, nessa distribuição de carga horária, não há espaço para as atividades complementares que são experiências teórico-práticas significativas de aprofundamento em áreas específicas de interesse dos licenciandos para inserção na iniciação científica, iniciação à docência e/ou na extensão, entre outras.

No tocante às dez competências gerais da BNCC a serem desenvolvidas como habilidades gerais da formação docente, saltam aos olhos quatro delas:

1 - [...] continuar aprendendo e colaborar para a construção de uma sociedade justa, democrática e inclusiva;

[...] 6 - [...] entender as relações próprias do mundo do trabalho e fazer escolhas alinhadas ao exercício da cidadania e ao seu projeto de vida com liberdade, autonomia, consciência crítica e responsabilidade;

[...] 8 -Conhecer-se, apreciar-se e cuidar de sua saúde física e emocional [...] 10 - Agir pessoal e coletivamente com autonomia, responsabilidade, [...] resiliência e determinação, tomando decisões com base em princípios éticos, democráticos, inclusivos, sustentáveis e solidários. (BRASIL, 2019b, p. 14 , grifos nossos).

Nos termos destacados neste trecho do documento, notam-se as discursividades que a governamentalidade produz, imbuídas de linguagem humanitária, de cidadania, liberdade, inclusão e democracia que remetem aos fins que esse currículo almeja quando institui tais competências. Afinal, "sob a égide neoliberal, a prática de desenvolvimento de competências está vinculada às ações de governamento das condutas dos outros e de si" (POSSA, BRAGAMONTE, 2018, p. 1061). Compreendendo currículo como "tecnologia cultural", vemos que ele está 
comprometido com a "produção de significados que dão às pessoas uma ideia de quem elas são e de quais serão seus futuros" (SIMON, 1995, p. 71). É por meio dessas tecnologias que o projeto neoliberal de Educação se estabelece em meio às disputas de poder, produzindo sujeitos dóceis, fáceis de serem capturados, empreendedores de si, homogêneos para o bom funcionamento dessa engrenagem.

São centrais na política educacional brasileira contemporânea os termos "cidadania" e preparação para "o mundo do trabalho". Isso pode ser observado desde a Constituição Federal (1988), a LDB (1996) e, mais recentemente, na BNCC (2017) e BNC-Formação (2019). Segundo Gallo (2018), essa presença faz parte do que o autor chama de processo de "governamentalidade democrática" e não tem relação com questões partidárias, mas com o fortalecimento de um Estado Democrático. Para ele, o Estado precisa de sujeitos participativos conformados com os princípios democráticos, daí, por meio de políticas educacionais e programas curriculares, pretende-se produzir um sujeito cidadão e trabalhador para governá-lo.

Os termos "flexibilidade" e "cooperação" compõem também a racionalidade neoliberal, um tipo de subjetividade que se almeja produzir. Para Foucault, o sujeito produzido pelo neoliberalismo é "essencialmente progressista no sentido de uma perpétua adaptação da ordem legal às descobertas científicas, aos progressos da organização e da técnica econômicas, às mudanças de estrutura da sociedade, às exigências da consciência contemporânea" (FOUCAULT, 2008, p. 224). Se a lógica é a do mercado, o sujeito que se espera é flexível, resiliente, que se adapte facilmente às situações encontradas no âmbito do trabalho, que possua iniciativa e esteja a postos para cooperar. Conforme Veiga-Neto (2018), os ditames neoliberais:

vão usar o currículo como grande operador dos códigos de verificação, permissões e interdições, do que é pensável e dizível aceitável e suportável. Tudo próprio de uma racionalidade que sustenta a articulação entre a economia e a política. E é claro que tudo isso será tão mais efetivo quanto mais precoce e imperceptível se der o processo de condução. (VEIGA-NETO, 2018, p. 42).

O sujeito interessado do neoliberalismo, ou seja, aquele que deseja comportamentos econômicos, não está dado, não é natural, mas é um produto desse ambiente discursivo (AVELINO, 2016). De forma que "seja sua vida coletiva como espécie ou os aspectos mais íntimos da sua existência como indivíduo, nada deve 
escapar à ação do governo" (AVELINO, 2016, p. 270). Essa reflexão com base foucaultiana nos faz compreender que as ideias de "liberdade" e "autonomia", tão utilizadas nas competências da política curricular em questão, são utopias. Esses dois termos, na racionalidade neoliberal, funcionam como tecnologias de governo de si. Por meio do discurso de liberdade e autonomia, deseja-se um sujeito ativo politicamente e que tenha instrumentos para governar a si mesmo. As condutas dos indivíduos são dirigidas, já estão estabelecidas, normalizadas e reiteradas às regras a que eles devem seguir e se autogovernar.

$\mathrm{Na}$ análise da racionalidade neoliberal operada por Foucault, é preciso entender que "o fato de a liberdade ser o cerne do governo liberal não significa que se esteja passando de um governo que teria sido até então autoritário a um governo que, agora, seria mais tolerante, flexível etc.". (DANNER, 2017, p. 80). O clamor da liberdade fundada na modernidade representa um tipo de "relação entre governantes e governados, uma relação em que a medida do 'pouco demais' de liberdade que existe é dada pelo 'mais ainda' de liberdade que é pedido" (FOUCAULT, 2008, p. 86). Isto é, o liberalismo não formula o "seja livre”, mas sim: “a gestão e a organização das condições graças às quais podemos ser livres" (p. 87).

Percebe-se também um grande foco dos pareceres nas competências socioemocionais, as quais os documentos afirmam serem imprescindíveis para que os estudantes aprendam a lidar com os desafios do séc. XXI. A racionalidade neoliberal defende que "não se pode dissociar o capital do indivíduo que o detém, ou seja, não se pode separar o conjunto das capacidades e das aptidões físicas e psicológicas do indivíduo que as detêm" (DANNER, 2017, p. 85).

Competências como "capacidade de abertura ao novo", "amabilidade", "autogestão", "engajamento com os outros" e "resiliência emocional" aparecem também como fundamentais a serem desenvolvidas. Conforme a 3 a versão do parecer, evidências científicas com base em estudos da psicologia indicariam que:

[...] o desenvolvimento delas promove avanços no aprendizado dos estudantes e impactam suas vidas no momento atual e no futuro, estas deixam de ser ocasionalmente promovidas por docentes bem-intencionados e passam a configurar como prática pedagógica altamente relevante, intencional e, no bojo da BNCC, obrigatórias. (BRASIL, 2019a, p. 16).

Tais competências compreendem também estratégias de governamento, mais especificamente, trata-se da tecnologia de autogoverno, ou seja, do governo 
de si. Conforme Foucault, o sucesso do poder está proporcionalmente relacionado àquilo que ele esconde de seus mecanismos (BAMPI, 2000). É por meio da subjetivação de indivíduos respeitosos, amáveis, resilientes, coletivos que se dará o governo de si. "Trata-se do exercício de um poder positivo, produtivo, que faz com que os indivíduos ao interiorizarem ideais [...] passam [sic] a viver e agir de determinada forma" (BAMPI, 2000, p. 15).

\section{DOCENTES PRÁTICOS, EXECUTORES E REGULADOS}

Todos os documentos analisados concordam que um dos princípios norteadores da formação em licenciatura é a centralidade na "prática". É nessa perspectiva que o documento da Proposta Inicial da BNC-Formação (BRASIL, 2018), como aponta em seu segundo capítulo, propõe mudanças nos cursos de Formação de Professores, além de outras específicas no curso de Pedagogia, tendo por base o que chama de uma visão sistêmica, buscando envolver não só os atores da educação, mas todas as políticas de formação docente, claramente configurando-se numa rede que intenta controlar por todos os lados a formação.

Conforme a proposta, para a formação inicial dos cursos de Licenciatura, era preciso superar a dicotomia entre teoria e prática, além da fragmentação curricular que tende a separar os conhecimentos pedagógicos dos "conhecimentos de conteúdo" a serem lecionados, e ainda superar a "teorização excessiva" dos cursos que não têm "respondido às demandas da contemporaneidade, aos resultados de aprendizagem e ao ensino de habilidades e competências previstas na BNCC" (BRASIL, 2018, p. 30). Há um descrédito em relação à formação teórica e reflexiva e um reducionismo na concepção da docência, já que a restringe a aprender habilidades e competências numa preocupação no "saber-fazer", o que transforma o docente em um técnico e reprodutor de pacotes pedagógicos e de práticas estabelecidas em contextos específicos.

Nessa perspectiva, a proposta pretendia ainda substituir o Estágio pelas Residências Pedagógicas inspiradas no modelo clínico de formação de médicos, em que o aluno sob supervisão de um professor do curso e de um docente experiente da escola deveria vivenciar a prática no ambiente escolar desde o primeiro semestre de curso. Essa substituição, no entanto, é suprimida a partir da 3a versão do parecer, em que a prática deverá ser realizada por meio do Estágio em situação real de trabalho e de maneira progressiva. Ainda que os documentos finais não 
mencionem a substituição, pode-se compreender como a ideia de Residência Pedagógica na Formação Inicial se coaduna com a concepção de formação presente nessa BNC-Formação. Conforme Silva e Cruz (2018), a prática desde o início do percurso formativo pode ser preocupante, pois denota que é na prática que o sujeito professor conhecerá sua área de atuação, numa visão utilitarista e esvaziada, sem o aporte suficiente de conhecimentos teóricos e políticos. Segundo as autoras, a Residência Pedagógica poderia ser um instrumento importante na formação dos licenciandos, mas numa concepção de totalidade desta.

Quando a finalidade da educação é preparar para o trabalho, o foco da formação docente se volta para prática em si. Discentes e docentes são vistos como mercadoria, em que a formação intelectual é subjugada. Não importa ao docente, nesse projeto neoliberal, ter uma formação teórica sólida que dê instrumentos para uma autoria de pensamento e autoria em sua prática, basta que tenha habilidades técnicas para aplicar o programa da BNCC que já está pronto.

As mudanças para o curso de Pedagogia na Proposta da BNC dividiria os quatro anos em três etapas: a 1a seria a base comum com duração de dois anos e destinada aos conhecimentos sobre a BNCC, políticas públicas em educação, didáticas e processo de aprendizagem; a 2ạa , chamada de aprofundamento de etapa, ocorreria no 3 o ano, sendo o momento em que os estudantes poderiam escolher entre três níveis de ensino para aprofundar conhecimentos, na educação infantil, alfabetização ou nos anos iniciais do ensino fundamental; por último, o $4^{\circ}$ ano seria destinado às disciplinas relacionadas à especialização em quatro áreas de atuação docente: a gestão escolar, a educação profissional, a didática do ensino superior e a educação especial. Essa proposta se ancora numa concepção de formação fragmentada e especializada do pedagogo, reduzindo o conhecimento deste a apenas parte do processo educativo, em detrimento de uma formação ampla e reflexiva que possibilite conhecimentos sobre todos os âmbitos da educação e a relação entre docência, pesquisa e extensão.

Na 3a versão do parecer, bem como no parecer homologado, essas etapas que subdividem a formação em Pedagogia vêm especificadas no Grupo II de Aprofundamento. Na versão homologada, houve a alteração da nomenclatura para "Cursos para formação de professores multidisciplinares" no lugar de "Licenciatura em Pedagogia", utilizado na 3a versão. O desejo de fragmentar, descaracterizar e enfraquecer a identidade profissional do pedagogo parece emergir até nos 
termos escolhidos pelo documento para definir tal curso de licenciatura. Ainda que os documentos mencionem a intenção de salvar a formação de professores da fragmentação, propõem que se formem profissionais especialistas por etapa escolhida, alheios à compreensão de todo o complexo fenômeno educacional. Ainda sobre isso, no Art. 22 da resolução, especifica-se:

Art. 22. A formação para atuar em Administração, Planejamento, Inspeção, Supervisão e Orientação Educacional para a Educação Básica, nos termos do art. 64 da LDB, ou com centralidade em ambientes de aprendizagens e de coordenação e assessoramento pedagógico, pode-se dar em:

I- cursos de graduação em Pedagogia com aprofundamento de estudos nas áreas de que trata o caput e que possuam uma carga horária mínima de 3.600 (três mil e seiscentas) horas; e

II- cursos de especialização lato sensu ou cursos de mestrado ou doutorado, nas mesmas áreas de que trata o caput, nos termos do inciso II do art. 61 da LDB.

$\S 1$ O O aprofundamento de estudos de que trata o inciso I será correspondente a 400 (quatrocentas) horas adicionais às 3.200 (três mil e duzentas) horas previstas para o curso de Pedagogia. (BRASIL, 2019c, p. 11).

Essa concepção constitui-se num retrocesso nas discussões daquilo que se construiu e foi instituído na DCN de 2015, em que a formação do licenciando era compreendida em sua totalidade, tendo conhecimento de todo o processo educativo, incluindo a gestão educacional. Assim, instituiu que os cursos contemplassem como conteúdo obrigatório a formação na área de políticas públicas e gestão da educação. A BNC concebe tal conhecimento como especialidade a ser proporcionada ao licenciando interessado em aprofundamento posterior de estudos no próprio curso ou em cursos específicos. Há, com isso, um retorno ao entendimento da formação de um docente instrumentalizado para executar e outro para pensar.

Nos documentos, aparece também uma exortação à aprendizagem do docente por toda a vida, o que é muito presente em políticas educacionais contemporâneas e está atrelado à ideia de sociedade do conhecimento, para a qual é preciso estar em constante movimento formativo, acompanhando as mudanças que ocorrem; isso se constitui em forma de governamento do sujeito docente, levando-o a responsabilizar-se pela sua capacitação e adequando-o ao modo de vida desejado (RESENDE, 2018). Na lógica neoliberal, o indivíduo deve investir em 
sua formação, pois é produzido como "empresário de si mesmo, sendo ele seu próprio capital, sendo para si mesmo seu produtor, sendo para si mesmo a fonte de sua renda" (FOUCAULT, 2008, p. 311). Nesse sentido:

Os neoliberais observam que, na verdade, o que se deve chamar de investimento educacional, em todo caso os elementos que entram na constituição de um capital humano, são muito mais amplos, muito mais numerosos do que o simples aprendizado escolar ou que o simples aprendizado profissional. (FOUCAULT, 2008, p. 315).

Chamam atenção também os novos marcos que os pareceres trazem para a formação de professores, entre eles: "[...] o compromisso para que todos os alunos possam ter assegurado o mesmo direito a aprendizagem"; "[...] engajamento com o autodesenvolvimento ao longo da carreira profissional"; "[...] articular a formação inicial com a formação em serviço numa perspectiva de aprendizagem ao longo da vida"; "Dar mais relevância às culturas colaborativas" (BRASIL, 2019, p. 18, grifos nossos). Esses marcos constituem-se em estratégias de regulação da prática docente. São utilizados para descentralizar o controle sobre tais sujeitos, de forma que cada um deverá se responsabilizar por si, por sua aprendizagem permanente, e poderá se autorregular compreendendo qual modelo de ser docente deverá ser seguido. Há nesses termos o alinhamento das "capacidades de autogovernamento dos sujeitos com os objetivos das autoridades políticas por meio da persuasão, sedução ao invés de coerção" (POSSA, BRAGAMONTE, 2018, p. 1062).

Todas as competências e conhecimentos esperados para a formação de professores fazem parte de um discurso que adquire estatuto de verdade e, de maneira sutil, multiplica-se nas políticas públicas educacionais e nas propostas curriculares, com a intenção de governar moralmente e guiar as condutas dos indivíduos. Assim, para garantir o controle da execução da BNC-Formação, o parecer e a resolução homologados estabelecem que o Inep deverá, no prazo para sua implementação, elaborar novo instrumento para avaliação dos cursos de formação docente, além de elaborar novo formato avaliativo do Enade para os cursos de formação de professores. Afirmam ainda que os cursos de formação que já tenham se adequado à DCN de 2015 não devem sofrer quebra de continuidade, devendo ajustar seus currículos para atender às novas competências sempre que necessitarem, dentro do prazo de 3 anos. Já os cursos de licenciatura que ainda 
não se adequaram às DCNs de 2015 deverão reformular seus currículos no prazo de 2 anos.

A ANPEd (ANPEd, 2018) e a Executiva Nacional dos Estudantes de Pedagogia discordam sobre essa normativa e defendem que se enfrente o real problema na formação de professor, que é a má qualidade da oferta dos cursos de formação de professor. Conforme o Censo do Ensino Superior de 2017, das matrículas nos cursos de Pedagogia, por exemplo, 83\% estão nas instituições privadas e parte desses cursos são realizados a distância. Isso é ainda mais relevante se considerarmos as últimas avaliações divulgadas pelo Inep em relação à diferença de desempenho entre universidades públicas e privadas (ExNEPe, 2019).

\section{CONSIDERAÇÕES FINAIS}

A partir da análise dos documentos, observa-se que a BNC-Formação está nitidamente traçada por razões econômicas e imbuída de um discurso técnico e científico que constitui expertises para legitimar e produzir verdades com a finalidade de conduzir ao êxito o projeto neoliberal de sociedade. A forma aligeirada e com diminuta participação dos diversos atores da educação já revela a concepção de docente da proposta. Para essa diretriz, o docente não tem participação nas decisões curriculares, ele é mero executor de um pacote pensado por outrem. É dessa forma que, desde a proposta inicial até a versão homologada, ínfimas alterações ocorreram, mesmo com manifestos e posicionamentos contrários de 30 entidades de docentes pesquisadores em educação e da formação do professor, de maneira que o documento final mantém preservado o caráter prescritivo, salvacionista, pragmatista, fragmentário e regulador.

Compreende-se que, por meio dessa diretriz curricular, com o aporte de tecnologias biopolíticas, intenta-se esquadrinhar e intervir na ação docente para garantir a governamentalidade da população, já que, gerindo a conduta do professor, almeja-se garantir também a conduta dos discentes que constituirá a classe trabalhadora e consumidora almejadas. Para tanto, a formação de professores tem de estar comprometida com a produção de sujeitos dóceis, autorresponsáveis, pragmáticos, resilientes, em nome de uma "educação de qualidade".

E, para controle dessa formação, nada melhor do que um currículo padronizado e ancorado em competências que funcionam como tecnologias do eu, por meio das quais, além de prestar contas, o docente, sob a racionalidade neolibe- 
ral, assume suas verdades, reflete sobre si, reconhece-se como um profissional que está dentro do padrão desejado ou não e redireciona sua conduta. O perfil docente esperado é o prático, sem aporte teórico para refletir sobre a realidade e questioná-la; os frutos dessa perspectiva de currículo neoliberal são: "produzir rotinas, aprisionar as forças, dividir, desanimar" (PARAíSO, 2015, p. 52). O resultado desse modelo de currículo é a "crescente flexibilização, desprofissionalização, substituibilidade, desqualificação, marginalização social, desvalorização salarial, esvaziamento político, enfraquecimento associativo e sindical" (SARAIVA; VEIGANETO, 2009, p. 199).

As possibilidades de movimento e de experimentações é o que dá vida ao currículo, é o que faz dele múltiplo e potente. Sabendo-se que as políticas públicas são construídas em campo permanente de disputas e que seus discursos de verdade são performativos, ou seja, elas só existem quando reiteradas, é possível questioná-las. Então, "é tempo de continuarmos o movimento, de intensificarmos nossos embates, de nos somarmos àqueles e àquelas que compartilham do desejo de estranhar o que nos impõem" (CARDOSO et al., 2019), e resistir, na perspectiva de Gallo, que é "re-existir, existir de novo, afirmar as potências da vida. Re-existir é recusar as subjetivações impostas e criar novas formas de subjetividade" (GALLO, 2017, p. 91). Não vamos, com isso, garantir a chegada a um destino ideal, se é que ele existe, mas ao menos nos recusaremos, hoje, ao que certamente não produz vida.

\section{REFERÊNCIAS}

ASSOCIAÇÃO NACIONAL DE PÓS-GRADUAÇÃO E PESQUISA EM EDUCAÇÃO. A política de formação de professores no Brasil de 2018: uma análise dos Editais Capes de Residência Pedagógica e Pibid e a reafirmação da Resolução CNE/CP 02/2015. Rio de Janeiro: Anped, 2018.

ASSOCIAÇÃO NACIONAL DE PÓS-GRADUAÇÃO E PESQUISA EM EDUCAÇÃO. Nota sobre a Base Nacional Comum para Formação de Professores. 21/12/2018. Rio de Janeiro: Anped, 2018.

AVELINO, N. Foucault e a racionalidade (neo)liberal. Revista Brasileira de Ciência Política, Brasília-DF, n. 21, p. 139-57, 2016.

BAMPI, L. R. Currículo como tecnologia de governo de cidadãos e cidadãs. Trabalho aprovado com resumo publicado na programação. In: REUNIÃO ANUAL DA ANPED, 23., 
24 a 28 de setembro de 2000, Caxambu, MG. Programa e resumos [...]. Rio de Janeiro: ANPED, 2000. p. 87.

BRASIL. Base Nacional Comum Curricular (BNCC). Educação é a Base. Brasília-DF: MEC/ Consed/Undime, 2017.

BRASIL. Conselho Nacional de Educação. Resolução CNE/CEP n. 2, de 1ำ de julho de 2015. Define as Diretrizes Curriculares Nacionais para a formação inicial em nível superior (cursos de licenciatura, cursos de formação pedagógica para graduados e cursos de segunda licenciatura) e para a formação continuada. Diário Oficial da União, Brasília, seção 1, 2 jul. 2015. p. 8-12.

BRASIL. Lei de Diretrizes e Bases da Educação Nacional. Lei n. 9.394, de 20 de dezembro de 1996. Estabelece as diretrizes e bases da educação nacional. Brasília-DF, 1996.

BRASIL. Ministério da Educação. Conselho Nacional de Educação. Diretrizes Curriculares Nacionais e Base Nacional Comum para a Formação Inicial e Continuada de Professores da Educação Básica. 3a Versão do Parecer (Atualizada em 18/09/19). Brasília-DF, 2019a.

BRASIL. Ministério da Educação. Parecer CNE/CP n. 22, de 7 de novembro de 2019. Diretrizes Curriculares Nacionais para a Formação Inicial de Professores para a Educação Básica e Base Nacional Comum para a Formação Inicial de Professores da Educação Básica (BNC-Formação). Brasília-DF, 2019b.

BRASIL. Ministério da Educação. Resolução CNE/CP n. 2, de 20 de dezembro de 2019. Define as Diretrizes Curriculares Nacionais para a Formação Inicial de Professores para a Educação Básica e institui a Base Nacional Comum para a Formação Inicial de Professores da Educação Básica (BNC-Formação). Diário Oficial [da] República Federativa do Brasil, Brasília-DF, 20 dez. 2019c.

BRASIL. Ministério da Educação. Proposta para Base Nacional Comum da Formação de Professores da Educação Básica. Brasília-DF, 2018.

CARDOSO, L. R. Queremos saber, queremos viver: governo do cotidiano no currículo experimental. Currículo sem fronteiras, v. 18, p. 943-62, 2018.

CARDOSO, L. R.; GUARANY, A. L. A., UNGER, L. G. S.; PIRES, M. A. Gênero em Políticas Públicas de Educação e Currículo: do direito às invenções. Revista E-curriculum, São Paulo, v. 17, p. 1458-79, 2019.

DANNER, F. Vida, poder, política: Foucault e a questão do liberalismo. Kalagatos, Fortaleza, v. 14, n. 2, 2017, p. 77-89, 2017. 
EXECUTIVA NACIONAL DE ESTUDANTES DE PEDAGOGIA [ExNEPe]. Boletim da Executiva Nacional de Estudantes de Pedagogia, [s.I.], n. 006, mar. 2019.

EVANGELISTA, O.; FIERA, L.; TITTON, M. Diretrizes para formação docente é aprovada na calada do dia: mais mercado. Jornal Universidade à Esquerda, Debate, 14 nov. 2019.

FOUCAULT, M. Nascimento da Biopolítica. Curso no Collège de France (1978-1979). São Paulo: Martins Fontes, 2008.

GALLO, S. A educação entre o governo dos outros e o governo de si. In: RESENDE, Haroldo de (Org.). Michel Foucault - a arte neoliberal de governar e a Educação. São Paulo: Intermeios, 2018. p. 211-25.

GALLO, S. Biopolítica e subjetividade: resistência? Educar em Revista, [s.I.], v. 33, n. 66, p. 77-94, nov. 2017.

MILLER, P; ROSE, N. Governando o presente: gerenciamento da vida econômica, social e pessoal. São Paulo: Paulus, 2012.

RESENDE, H. A educação por toda a vida como Estratégia de Biorregulação Neoliberal. In: RESENDE, Haroldo (Org.). Michel Foucault - a arte neoliberal de governar e a Educação. São Paulo: Intermeios, 2018, p. 77-94.

ROSE, N. Governando a alma: a formação do eu privado. In: SILVA, Tomaz T. (Org.). Liberdades reguladas - a pedagogia construtivista e outras formas de governo do eu. Petrópolis: Vozes, 1998. p. 30-45.

PARAísO, M. A. Um currículo entre formas e forças. Educação, Porto Alegre, v. 38, n. 1, p. 49-58, 2015.

POPKEWITZ, T. S. História do Currículo, regulação social e poder. In: SILVA, Tomaz T. (Org.). O sujeito da educação: estudos foucaultianos. 6. ed. Petrópolis: Vozes, 1994. p. 173-210.

POPKEWITZ, T. S. Lutando em defesa da alma: a política do ensino e a construção do professor. Tradução de Magda França Lopes. Porto Alegre: Artmed Editora Ltda., 2001.

POSSA, L. B.; BRAGAMONTE, P. L. A. Uma Possível Arte de Governar a Formação de Professores Alfabetizadores. Revista Ibero-Americana de Estudos em Educação, Araraquara, v. 13, p. 1050-65, 2018.

SIMON, R. I. A Pedagogia como uma tecnologia cultural. In: SILVA, Tomaz Tadeu da (Org). Alienígenas na sala de aula: uma introdução aos estudos culturais em educação. 
Petrópolis: Vozes, 1995. p. 61-84.

SARAIVA, K.; VEIGA-NETO, A. Modernidade líquida, capitalismo cognitivo e educação contemporânea. Educação \& Realidade, Porto Alegre, v. 34, n. 2, p. 187-201, maio/ago. 2009.

SILVA, K. A. C. P.; CRUZ, S. P. A. Residência Pedagógica na formação de professores: história, hegemonia e resistências. Momento diálogos em educação, Rio Grande, v. 27, n. 2, p. 227-47, 2018.

VARELA, J. Categorias espaço-temporais e socialização escolar: do individualismo ao narcisismo. In: COSTA, Marisa Vorraber (Org.). Escola básica na virada do século: cultura, política e currículo. São Paulo: Cortez, 1999. p. 73-106.

VEIGA-NETO, A. Neoliberalismo e Educação: Os desafios do precariado. In: RESENDE, Haroldo de (Org.). Michel Foucault - a arte neoliberal de governar e a Educação. São Paulo: Intermeios, 2018. p. 33-44.

\section{Sobre as autoras:}

Manuella de Aragão Pires: Mestranda em Educação na Universidade Federal de Sergipe (UFS), São Cristóvão. Grupo de Estudos e Pesquisas em Educação Científica. Técnica em Assuntos Educacionais no Departamento de Apoio Didático Pedagógico (DEAPE) na Pró-Reitoria de Graduação da Universidade Federal de Sergipe. Pesquisa na área de currículo, gênero e sexualidade. E-mail: manuelladearagao@yahoo.com.br, Orcid: http://orcid.org/0000-0003-2854-984X

Lívia de Rezende Cardoso: Doutora em Educação pela Universidade Federal de Minas Gerais (UFMG). Professora associada I da Universidade Federal de Sergipe (UFS), São Cristóvão, Programa de Pós-Graduação em Educação, Líder do Grupo de Estudos e Pesquisas em Educação Científica. E-mail: livinha.bio@gmail.com, Orcid: http://orcid.org/0000-0003-4091-9110

Recebido em: 18 de julho de 2020 Última revisão: 5 de setembro de 2020 Aprovado em: 9 de setembro de $\mathbf{2 0 2 0}$ 
